\title{
What do the general public think about maps as art?
}

\author{
William Cartwright ${ }^{\mathrm{a}, \mathrm{b}}$ * \\ ${ }^{a}$ School of Science, RMIT University, Australiawilliam.cartwright@rmit.edu.au \\ ${ }^{b}$ Cartwright $\mid$ Geo $\mid$ Consulting cartwright.geo.consulting@gmail.com \\ * Corresponding author
}

Keywords: Cartography, Art, public perception

\begin{abstract}
:
This paper describes the outcomes of the Fourth Stage of research that was conducted to determine whether the idea of 'Emotional Architecture' - conceived by architect Luis Barragán and artist Mathias Goéritz in 1953 to describe an architecture elevated to art for the purpose of inspiring emotion (Suri, 2017) - could be applied to maps. Maps considered to be art are not maps that 'look' like a certain artistic style or impression, but something that, as an individual 'stand-alone' piece of art would be considered to be art.

This fourth experiment was conducted with the general public. The three previous experiments were conducted with professional British cartographers (Experiment 1), students undertaking a Master's degree course in Cartography (Experiment 2) and international cartographers (Experiment 3). As the first two experiment results could be biased by the very nature of the candidates, this fourth experiment was conducted with the general public.

The method used in all four experiments was based on Kennick's 'Warehouse Theory' (1958). What Kennick says about Warehouse Theory is:

"a person is directed to remove all the art objects from a huge warehouse which contains a great variety of things. The individual is able to select the art objects "with reasonable success" even though he employs no definition of art in terms of a common denominator. A work of art is known when seen. On the other hand, the same individual is at a loss when instructed to bring out all the expressive objects or all those which possess significant form, because the person does not recognize what expressiveness and significant form are."
\end{abstract}

Using Amazon's Mechanical Turk platform, participants were asked to consider 21 map images provided. They were instructed thus:

"If you were asked to go into a warehouse and "bring out the art" (with no other instructions provided), which maps would you select as 'art'. Please note the map(s) that you consider to be art by checking the radio button beside each of your selections. (There is no maximum or minimum selection.)"

After providing some general details about themselves, they selected those maps that they considered to be Art. 268 international participants completed this experiment.

This paper will report on the findings from Experiment 4.

\section{References:}

Kennick, W., 1958, “Does Traditional Aesthetics Rest on a Mistake?”, Mind, Vol. 67, No. 267, pp. 317-334.

Suri, 2017, "Inside the Rise of Emotional Design”, Architectural Digest,

https://www.architecturaldigest.com/story/emotional-design web page accessed 5 August 2019. 